\title{
Complete Pentalogy of Cantrell: A case report and a review of literature
}

\author{
*Shwe DD, B.M., B.Ch., FMCPaed, *Toma BO, B.M., B.Ch., FWACP *Ogbu \\ O, B.M., B.Ch., **Shitta Ah, B.M., B.Ch., FWACPS, ** Prof Chirdan, LB, B.M., \\ B.Ch., FWACS \\ *Department of Paediatrics, Jos University Teaching Hospital, Jos, \\ **Department of Surgery, Jos University Teaching Hospital, Jos.
}

\begin{abstract}
Pentalogy of Cantrell is a rare congenital malformation syndrome involving specific combination of ventral midline defects with ectopia cordis', as the most severe malformation. The complete form consists of five anatomical defects. We report a case of a one hour old female neonate delivered to a 27 year old primipara who presented with the complete form of the syndrome. She had surgery on the $4^{\text {th }}$ day of life, however died 36 hours after surgery. We report this rare congenital anomally and a review of relevant literature.
\end{abstract}

Keywords: Abdominal wall defect, Ectopia cordis, Pentalogy of Cantrell

\section{Introduction}

The pentalogy of Cantrell was first described in 1958. ${ }^{1}$ It is also known as Cantrell-Haller-Ravitch syndrome named after the initial authors. ${ }^{2}$ The cardinal features of the syndrome were anterior abdominal defect (omphalocele) in association with ectopia cordis (EC) (evisceration of the heart). Toyama (1972) subsequently described the full spectrum of the Cantrell's syndrome to consist of ectopia cordis, a defect in the diaphragmatic pericardium, a deficiency of the anterior diaphragm, lower sternal defect, a midline supraumbilical abdominal wall defects, various structural congenital intracardial anomalies. ${ }^{3}$

The precise cause of Pentalogy of Cantrell has remained elusive. One hypothesis that has enjoyed wide acceptance is that it results from a developmental failure of a segment of the lateral mesoderm at about the $14^{\text {th }}$ to $18^{\text {th }}$ days of intrauterine life, with subsequent failure in the development of the transverse septum of the diaphragm and the failure in the ventromedial migration of the paired mesodermal folds of the upper abdomen., ${ }^{1,4}$

Complete Cantrell's Pentalogy is rare; the estimated prevalence varies from $1 / 65,000$ to $1 / 200,000$ births, affecting male and female fetuses at a ratio of 2:1. Affected females usually present more severe symptoms. ${ }^{5}$ The risk of recurrence is quite small. There are no documented teratogens linked to this condition. Association with aneuploidy, especially with trisomy 18, has been described and therefore, prenatal chromosomal studies is highly desirable. ${ }^{6-8}$ The thoraco-abdominal syndrome including the pentalogy of Cantrell is suggested to be an X-linked dominant disorder, with mapped Xq24-q27 gene. ${ }^{7}$ There are few cases reported from Africa, mostly from Nigeria and these are mainly of the incomplete type. ${ }^{9,10}$ To the best of our knowledge, only a few cases of complete Pentalogy of Cantrell have been reported.

\section{Case report}

Baby A R, a $1 \mathrm{hr}$ old female newborn delivered through a Caeserian-section to a $27 \mathrm{yr}$ old primipara at term, presented in special baby care unit of the Jos University Teaching Hospital (JUTH). She was referred from a near-by secondary level hospital on account of evisceration of the heart, liver, intestine, bifid and hypoplastic sternum. In addition, she had spina bifida oculta. There was however, no craniofacial or limb abnormalities. She had respiratory distress and hypothermic at presentation. APGAR scores were said to be 8 and 9 at first and fifth minutes respectively. She weighed $2.7 \mathrm{~kg}$ at presentation.

The first trimester of pregnancy was complicated by recurrent febrile illness that required hospitalization and treatment with several intravenous antibiotics. The mother subsequently developed repeated vaginal bleeding during the first trimester of pregnancy and was admitted for bed rest. Obstetrics scan done at about $10^{\text {th }}$ week's gestation revealed two gestational sacs. One of which was said to suggest the presence of a viable fetus while the second sac appeared empty. Twin gestation was suspected. When the vaginal bleeding persisted, she was evaluated to have an inevitable abortion and subsequently had a manual vacuum aspiration (MVA). She also received an abortificient (oxytocin). There was no history suggestive of exposure to ionizing agents. When pregnancy signs persisted despite the MVA about 2 weeks later, repeat pregnancy test was positive and a second obstetrics scan revealed similar findings as the former. By this time, vaginal bleeding had stopped. Pregnancy was carried to term. No family history of consanguinity or congenital anomalies. 
The patient was admitted into the neonatal intensive care unit (NICU) at about $1 \mathrm{hr}$ of life and was nursed in an incubator. The eviscerated heart and the abdominal organs were covered with an improvised silo (urine bag). Preliminary echo showed thicken dilated left ventricle, ventricular septal defect (VSD) and a dilated inferior vena cava (IVC). She was started on IV antibiotics and dextrose infusion and intranasal oxygen after relevant laboratory specimens had been taken. Blood culture did not yield any growth. Biochemical and haematological indices were essentially normal.

By the $4^{\text {th }}$ day into hospital admission, the patient had minimal dissection and posterior displacement of the heart. Two rotational / advancement fascio-cutaneous flaps were raised from the abdomen, advanced and rotated to cover the ectopia cordis, as the thoracic skin defect was too wide. A gortex mesh was also used to increase the abdominal cavity to make space for the displaced liver. She also had bilateral chest tubes inserted. Patient was also placed on ventilatory support, $\mathrm{O}_{2}$ saturation ranged between $94-96 \%$. Post ops $\mathrm{Hb}$ was $17.3 \mathrm{gdl}$ and renal function tests remained normal. Abnormal biochemical changes immediate post ops were fluctuating serum glucose levels between $11-20 \mathrm{mMol} / \mathrm{L}$ with associated temperature subnormality $\left(35.8^{\circ} \mathrm{C}\right)$ despite the standard incubator care.

By $30 \mathrm{hr}$ post op, child developed repeated apnoea attacks. Efforts at resuscitation were not successful and she was subsequently certified clinical dead. Caregivers were counseled for autopsy but declined consent.

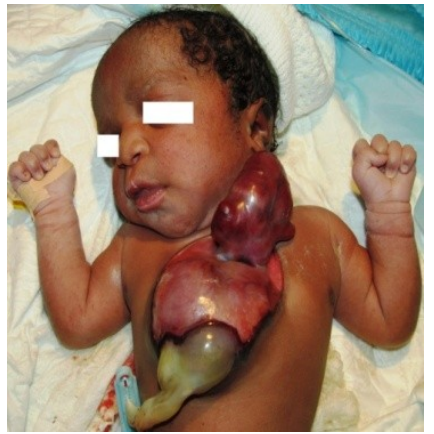

(a)

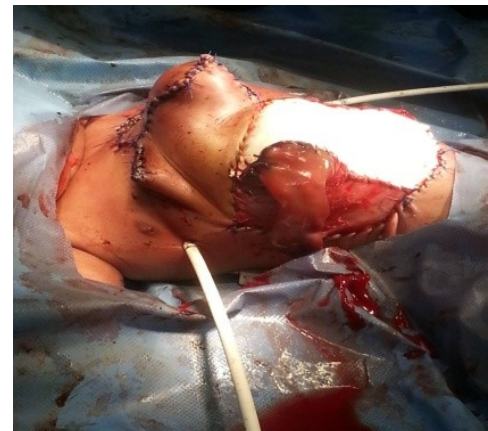

(b)

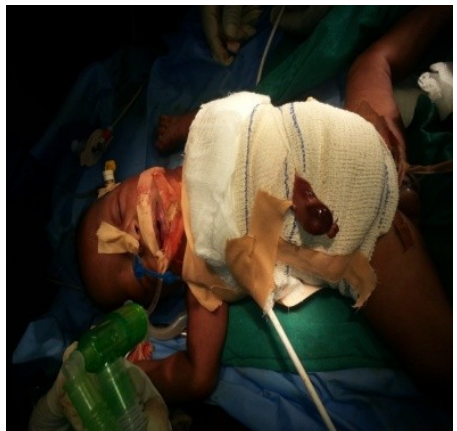

(c)

Figures a, b and c: Pentalogy of Cantrell: Clinical photographs of patient (At presentation and immediate post ops)

\section{Discussion}

Cantrell's pentalogy (POC) is a very rare structural congenital syndrome with an estimated incidence put at 5.5 per 1million live births. ${ }^{10}$ One case of POC was reported from AKTH, Kano, (Mukhtar-Yola et al, 2012). To date, well below 100 reported cases documented in the literature and their case file were not large. It is described as a deficiency of the anterior diaphragm, a midline supraumbilical abdominal wall defects, and a defect in the diaphragmatic pericardium, various structural congenital intracardial anomalies and lower sternal defect. $^{2}$ The syndrome has variable expressivity with majority of those reported having the incomplete variant. Although, autopsy could not be performed in the case presented, the only group of other structural defect observed was the dimple on the lumbosacral region suggestive of a spinal bifida oculta. Echocardiographic findings did not demonstrate ASD (53\%), Tetralogy of Fallot (20\%) and ventricular diverticulum (20\%) respectively, as reported in literature. ${ }^{1}$ Various other anomalies reported by other authors which were not present in this current case were craniofacial and other CNS anomalies such as cleft lip/palate, encephalocele, hygrocephalus and craniorachischisis. ${ }^{12-14}$ Limb defects such as clubfoot, absent tibia or radius and hypodactyly were also absent. ${ }^{15,16}$

Toyama MW (1972) described this rare syndrome in 3 classes: Class 1: Exact diagnosis with all five defects present. Class 2: Probably diagnosis with four defects (including intracardiac and anterior abdominal wall defects) present and Class 3: Incomplete diagnosis, with combination of defects where sterna defects is always present. The female neonate presented in this case appeared to have exhibited a complete spectrum of the Pentalogy of Cantrell (Toyama Class-1 POC). ${ }^{5}$

POC is said to results from a developmental failure of a segment of the lateral mesoderm at about the $14^{\text {th }}$ to $18^{\text {th }}$ days of intrauterine life, with subsequent failure in the development of the transverse septum of the diaphragm and the failure in the ventromedial migration of the paired mesodermal folds of the upper abdomen. ${ }^{1,4}$ Through this gap, the heart and the abdominal viscera protrude causing ectopia cordis and gastroschisis respectively.

Depending on the location of the protruding heart, and extend of the abdominal wall defect, ectopia cordis can be divided into cervical, cervicothoracic, thoracic, thoraco-abdominal and abdominal typologies. The commonest is the thoraco-abdominal (Tausing HB, 1982). Here the body wall defect usually extends into the umbilicus. ${ }^{17}$ The patient presented in this report had the thoraco-abdominal typology. 
Pentalogy of Cantrell is sometimes found in Edward, Patau and Turner syndromes. ${ }^{18,19}$ The mutagens linked to the POC include environmental, pharmacological, chemical, radiological etc. ${ }^{20,21}$ In this case presented, no evidence of known maternal exposure to any of these mutagens except for the history of multiple antibiotics use, abortificient and MVA which the mother received during early first trimester of pregnancy. The neonate also did not have dysmorphic features suggestive of a chromosomal disorder. To the best of our knowledge, there is no case of Cantrell's pentalogy associated with any intrauterine infection to date. ${ }^{21}$

Prenatal diagnosis of POC by obstetrics ultrasound scan at first trimester has developed significantly over the years since its first report in $1991 .^{22}$ This is thought to help in the planning for appropriate management before delivery. It would also provide information for parental counseling. Intrauterine diagnosis of this pentalogy is impossible before $12^{\text {th }}$ week of gestation, because of herniation of bowel out of abdomen is a normal event in fetal development at this time, but after that, ultrasonography is a useful method even in the first trimester. ${ }^{23}, 24$ Both 2D and 3D obstetric ultrasonographies are recommended, but 3D ultrasonography is not necessary in the first trimester of pregnancy. ${ }^{23}$ In this present case, the mother had ultrasound scan at $1^{\text {st }}, 2^{\text {nd }}$, and $3^{\text {rd }}$ trimesters of pregnancy, two gestational sacs were seen with one said to have been empty. Could it have been the omphalocoele that was wrongly reported as the empty gestational sac? Other diagnostic methods including CT-Scan and MRI can be used for confirmation. ${ }^{25,26}$ These facilities were however not available at the referring hospital.

Usually, termination of pregnancy is advised if fetus is not viable. If viable however, vaginal delivery is desirable since Caesarean delivery has not been shown to improve prognosis over vaginal delivery. ${ }^{27,28}$ The indication for a $\mathrm{C}$ - section in this case was a breech presentation with unfavorable cervix.

Differential diagnosis include: Isolated ectopia cordis by amniotic band syndrome, isolated gastroschisis or omphalocele, Beckwith-Weidemann syndrome and Body stalk anomaly. Treatment is multidisciplinary, comprising of team of neonatologist, paediatric cardiologist, paediatric surgeons, plastic surgeons, anaesthesiologists etc. ${ }^{29} \mathrm{~A}$ multidisciplinary team was similarly assembled for the management of the current case. The team decides the approach to the child's care. Care essentially involves immediate temperature control, coverage of the herniated viscera with a silo bag. Previously, the surgery was planned in stages with the coverage of thoracic defect first, the omphalocele repair is planned. Should the infant survive for at least 3 months, the repair of the intracardiac defects is undertaken. Currently, single stage operative procedure is favored but is plagued with a lot of challenges. ${ }^{30}$ Our patient had a single staged procedure performed by a combined team of paediatric, plastic and cardiothoracic surgeons. She however, demised suddenly 30 hours post up. Unfortunately, the parents declined autopsy. The Survival rate for those with Class 1 POC is said to be less than $20 \%{ }^{1}$

\section{Conclusions}

Pentalogy of Cantrell is a rare congenital anomaly. In every prenatally diagnosed omphalocele, POC should be excluded. This case presented was Toyama Class 1 POC. The preferred approach to management still needs to be established in resourced constrained countries like ours.

\section{References}

[1]. Cantrell JR, Heller RJA, Ravitch MM, : A syndrome of congenital defects involving the abdominal wall, sternum, diaphragm, pericardium, and heart. Surg. Gynecol.Obstet. 1958;107(5):602-14

[2]. Robinson JN, Abuhamad AZ. Abdominal wall and umbilical cord anomalies. Clin Perinatol 2000; 27: $947-78$.

[3]. Toyama WM.: Combined Congenital defects of the anterior abdominal wall, sternum, diaphragm, pericardium and heart: a case report and review of the syndrome. Pediatrics 1972, 50:778-779.

[4]. Peixoto-Filho FM, Cima LC, Nakamura Pereira M. Prenatal diagnosis of pentalogy of Cantrell in the first trimester: Is 3 dimensional ultrasonography needed? J Clin Ultrasound 2008; 37:112-14.

[5]. Bonilla-Musoles F, Machado LE. Gastrointestinal tract and internal abdominal wall. In: Kurjak A, Chervenak FA, Carrera JM (Eds). Atlas of fetal anomalies. Jaypee Brothers Medical Publisher 2007;174-94

[6]. Chen CP. Syndromes and disorders associated with omphalocele (II): OEIS complex and pentalogy of Cantrell. Taiwan J Obstet Gynecol 2007; 46: 103-10.

[7]. Desselle D, Fellow R, Herve P, Toutain A, Lardy H, et al. Pentalogy of Cantrell: Sonographic assessment. J Clin Ultrasound 2007; 35: 216-20.

[8]. Zidere V, Allam LD. Changing findings in pentalogy of Cantrell in fetal life. Ultrasound Obstet Gynecol 2008; $32: 835-37$.

[9]. Adebo OA, Arowolo FA, Osinowo O, Sodeinde O. Ectopia cordis in a Nigerian child. West Afr J Med. 1993 Oct-Dec;12(4):233-5.

[10]. HU Okafor, Tagbo Oguonu, SN Uwaezoke, BC Anusiuba. A variant of pentalogy of cantrell in a live birth. Case Report. 2011; 14(1): $106-108$.

[11]. Carmi JR, Boughman JA: Pentalogy of Cantrell and associated midline anomalies: a possible ventral midline developmental field. Am J Med Genet (1992) 42:90-95.

[12]. Correa-Rivas MS, Matos-Llovet I, Garcia-Fragoso L: Pentalogy of Cantrell: a case report with pathologic findings. (2004), Paediatr DEV Pathol 7:649-652. [PubMed]

[13]. Morales JM, Patel SG, Duff JA, Villareal RL, Simpson JW : Ectopia cordis and other midline defects. Ann Thorac Surg (2000)70:111-114.[PubMed]

[14]. Polat I, Gul A, Aslan H, Cebeci A, Ozseker B, Caglar B, Ceylan Y: Prenatal diagnosis of Pentalogy of Cantrell in three cases, two with craniorachischisis. J Clin Ultrasound (2005) 33:308-311.[PubMed] 
[15]. Pivnick EK, Kaufman RA, Velagaleti GV, Gunther WM, Abrmovici D: Infant with midline thoracoabdominal schisis and limb defects. Teratology 58: 205-208.[PubMed]

[16]. Uygur D, Kis S, Seener E, Gunce S, Semerci N: An infant with Pentalogy of Cantrell and limb defects diagnosed prenatally. Clin Dysmorphol 13:57-58. [PubMed]

[17]. Kim KA, Vincent WR, Muenchow SK, Wells WJ, Downesy SE. Successful repair of ectopia cordis using alloplastic materials. Ann Plast Surg 1997;38.518-522

[18]. Martin RA, Cunniff C, Erickson L, Jones KL. Pentalogy of Cantrell and ectopia cordis, a familial developmental field complex. Am J Med Genet 1992; 42(6): 839-41

[19]. Spitz L, Bloom KR, Milner S, et al: Combined anterior abdominal wall, sterna, diaphragmatic, pericardial and intracardiac defects: A report of five cases and their management. J Pediatr Surg 1975;10.491-59.

[20]. Agarwal R. Prenatal Diagnosis of Anterior body wall defects: a pictorial essay. Ind J Radiol Imag. 2005;15(3).361-372

[21]. Kasper, Baunwald et al (Ed). Harrison's Principles of Internal Medicine. In-Infectious diseases. (Ch-16). Toxoplasmosis. $16^{\text {th }}$ Ed. Vol-1, Mc Graw Hill, NewYork. 2000.p1243.

[22]. Bennett TL, Burlbaw J, Drake CK, Finley BE: Diagnosis of ectopia cordis at 12 week's gestation using transabdominal ultrasonography with color flow Doppler. J Ultrasound Med. 1991,10: 695-696.

[23]. Peixoto-Filho FM, do Cima LC, Nakamura-Pereira M. Prenatal diagnosis of Pentalogy of Cantrell in the first trimester: is 3dimensional sonography needed? J Clin Ultrasound. 2009;37(2):112-4.

[24]. Sarkar P, Bastin J, Katoch D, Pal A. Pentalogy of Cantrell: diagnosis in the first trimester. J Obstet Gynaecol. 2005;25(8):812-3.

[25]. Ghidini A, Sirtori M, Romero R, Hobbins JC. Prenatal diagnosis of pentalogy of Cantrell. J Ultrasound Med. 1988;7(10):567-72.

[26]. Haynor DR, Shuman WP, Brewer DK, Mack LA. Imaging of fetal ectopia cordis: roles of sonography and computed tomography. J Ultrasound Med. 1984;3(1):25-7.

[27]. Snyder CL, St Peter SD,: Trends in mode of delivery for gastroschisis infants. Am J. Perinatol. 22:391-396, 2005.

[28]. Snyder CL. Outcome analysis for gastroschisis. J. Pediatr. Surg 34: 1253-1256, 1999.

[29]. Jeroen H. L. van Hoorn, Rob M. J. Moonen, Clément J. R. Huysentruyt, L. W. Ernest van Heurn, Jos P. M. Offermans, and A. L. M. Twan Mulder. Pentalogy of Cantrell: two patients and a review to determine prognostic factors for optimal approach. Eur J Pediatr. 2008 January; 167(1): 29-35.

[30]. Junji T, Kitamura, Tsuji K, et al: Pentalogy of Cantrell with a Double outlet right ventricle: 3.5 yrs followup in a prenatally diagnosed case. Eur J Pediatr. 2008; 167. 